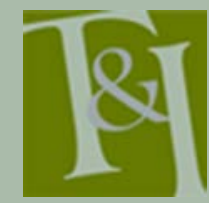

The International Journal for Translation \& Interpreting Research trans-int.org

\title{
Conflict, opacity and mistrust in the digital management of professional translation projects
}

\author{
Elisa Alonso \\ Universidad Pablo de Olavide \\ elialonso@upo.es
}

DOI: 10.12807/ti.108201.2016.a02

\begin{abstract}
This paper is aimed at exploring the computer-mediated communication that takes place during the management of translation projects. More specifically, we will analyse the nature of communication among the actors involved in a translation project, and will outline the existing sources of conflict. Our methodology approach, qualitative and interpretative, was based on two focus group sessions, of approximately one hour each, where a total of five translation professionals participated. We have found that communication between clientsmanagers and translators was mainly virtualised (email and translation project portals). The translators reported that, very frequently, after accepting a translation project, they felt cheated by clients-managers, because, apparently, changing volume, deadlines, translation tools and even the texts to be translated are common practices. Some translators questioned the professionalism of managers and pointed to their lack of training, while others complained about the existence of very complicated instructions (super skopos) imposed by the client/manager. As a result, a number of tensions appeared in the management of the project, forcing a loop of continuous negotiation and renegotiation.
\end{abstract}

Keywords: project management, professional translation, computer-mediated communication, translation production networks, conflict

\section{Introduction}

Communication among translation professionals has become to a large extent a computer-mediated activity. Particularly in the case of freelancers and SLVs (single language vendors), translation as an activity takes place in online labour markets as defined by Horton (2012) or computer-mediated markets (Steinfield et al., 2006). More particularly, within Translation Studies, Kuznik and Verd (2010) documented the increasing importance of management tasks and outsourcing practices in the professional context of translation. Likewise, Abdallah (2007, p. 674) pointed out how globalisation has impacted on the traditional structure of translation activity (the client, the translator and the end user of the translation) shaping new translation production networks, where the client and the translator no longer have direct contact because of the emergence of a myriad of intermediaries.

It is well known that previous works have documented the humancomputer interactions that take place among translators, using different methodological approaches, such as interviews, focus groups, surveys, analysis of translators' forums, ethnographical observation, etc. (among others, Lagoudaki, 2006; Désilets et al., 2009; Olohan, 2011; Torres, 2012; Guerberof Arenas, 2013). In parallel, other works have been aimed at exploring the social and professional nature of translation activity (among others, Mayoral, 
2001; Risku 2004; Gouadec, 2005; Monzó Nebot, 2006; Katan, 2009; Dam \& Zethsen, 2011; Calvo, 2015).

This contribution emanates from a $\mathrm{PhD}$ research project (Alonso, 2014b) aimed at exploring the role of translation professionals in the information society, how they conduct their work, the needs they experience, and the tools and human resources they resort to when translating.

In this paper, assuming the centrality of technology in translation workflows (Alonso and Calvo, 2015), we will analyse the discourse of five translation professionals (freelancers and single language vendors) that participated in two focus group sessions in 2013.

In previous works already published by the author, a number of trends arose suggesting that (a) technology is omnipresent in the translation process and that translators have a positive overall perception of translation tools and of translator colleagues, reviewers and experts with whom they interact in the translation phase (Alonso, 2015a); (b) generic tools such as Google and Wikipedia - and in general, the Internet - are as important to translators as computer-assisted translation (CAT) tools or machine translation (MT) technology (Alonso, 2015b); and (c) most interactions that take place between human translators and computers have a positive nature (Alonso, 2014a).

In this paper we will focus on a scarcely explored area within Translation Studies, i.e. the conflict that seems to surround the management of translation projects and the negative interactions that sometimes take place between translation professionals and technology.

In other disciplines, there are precedents that have documented the impact of virtual forms of communication such as email in organisations. For example, in the field of Information Sciences, Hössjer and Severinson Eklundh (2009) stressed the different approaches of in-house workers and remote-environment workers in a newspaper newsroom and concluded:

The picture that emerges from the analysis of our data differs from what has been found in other studies about email. Rather than creating encounters between people, or bridging social barriers, we have found that the effect of email has been rather the opposite. Hierarchical structures have been reinforced between different co-worker groups in the newsroom. Highly variable and multidimensional communication (face-to-face, telephone etc.) goes on within these groups (in the near or immediate environment), but to a very limited extent across the groups (in the remote environment), resulting in a communicative gap in the newsroom environment as a whole. [...] The communication maintained among workers in the remote environment, however, builds primarily on email as one-way communication: short, conventionalized messages containing information of different kinds related to the news work. [...] The email communication in the remote environment is in this regard not of an in-depth character and does not balance the communicative gap observed in the newsroom environment. (pp. 38-39).

In the field of Communication, Turnage (2007, p. 54) supports the idea of not blaming the medium (email) when conflict arises, since "the majority of messages in an organization are understood within the framework of its specific norms and culture".

Stressing the importance of trust and conflict in virtual organisations, Business Management researchers Panteli and Sockalingam (2005) have determined that:

[...] the emergence of new forms of virtual organizing require a careful repositioning of trust types, an appreciation of the varied potential for the different forms of conflict and an understanding of the dialectical relationship between both phenomena. (p. 613). 
There are also some interesting precedents in the field of translation. Yahaya (2009) carried out a case study of translation project management within the United Nations by using a virtual space, and documented some of the benefits and challenges of the process. In line with this, Stoeller (2011) explored the impact of global virtual teams on localization project management, stressing the importance - again - of considering cultural differences (Hofstede et al., 2005 cit. Stoeller 2011, p. 300) and building trust (p. 307) in global virtual teams. Likewise, Abdallah (2007) has argued that a lack of trust is the Achilles' heel of translation production networks:

Trust building therefore entails that the perspectives and interests of each stakeholder are addressed, knowledge is shared, and information is clear, accountable and legitimate as far as all parties are concerned. According to our findings, these factors are not among the strengths of the translation production networks. (pp. 677-678).

She goes on to note that conflict appears when professional ethics are confronted with the demands and practices of working life (2007, p. 681), while observing in a later work (2011) that:

The results of these analyses suggested that production networks manifest themselves as a challenging working environment, as pressures from the rest of the network may impose certain behavior on translators, despite their desire to act ethically in the interest of the user. The translator interviews revealed dilemmas of collective action, with severe problems arising from asymmetric information and goal conflicts between principals and agents. (pp. 38-39).

A number of the issues raised by these authors have also emerged from the narratives in our focus groups, since conflict and mistrust seemed to appear during the management tasks of a translation project (email, translation portals, negotiation between translators and clients or project managers).

In the following sections, we will first describe the method used in our research; then we will analyse the results of our qualitative research based on focus groups outlining the sources of conflict, opacity and mistrust in the context of professional management of translation projects. After briefly discussing the results, we will present some suggestions for future areas of research.

\section{Methodology}

Our method is empirical, qualitative and interpretative, and is based on two focus group sessions, each one lasting approximately one hour, with a total of five translation professionals.

To recruit these people we searched the contacts of our LinkedIn network (a total 315 contacts) and selected a total of 17 individuals who fulfilled our criteria, i.e. they were all translation professionals (and, as a result, they could contribute meaningfully to our focus group sessions). It should be noted that our selection strategy was to a large extent inductive, since we did not established a set of profiles in advance. We would also like to point out that recruiting individuals for an empirical work is never achieved without difficulties, particularly in face-to-face interviews or focus groups of professionals, and when the project is unfunded, as in our case.

We contacted each selected professional individually through their LinkedIn email and invited them to take part in our sessions. After various email exchanges aimed at checking profiles, credentials and availability, a total of five individuals were selected. As professionals working in the translation sector, these individuals all met the criteria of our study. They also 
constituted a significant sample with varied profiles in terms of specialisation, work status, age, gender, experience and background. We acknowledge, however, that this research is inevitably biased by its language/country focus, since all participants had Spanish as their mother tongue and lived in Spain.

We organised two focus group sessions to fit the participants' availability, and the author of this paper acted as the moderator. The focus-group sessions followed the sequence described by Robson (2011, pp. 280-284) and consisted of a fluent, semi-structured - and we would add fruitful - exchange of views among participants, conducted in a relaxed environment. Firstly, participants were asked about their background, specialisations, experience, languages, etc. Then, each of them described their way of approaching a translation brief: the tools they used, how they organised their work, the needs they had during the translation process, their relationships with other relevant agents (project managers, clients, other translators), etc.

Adhering to the qualitative research method of interviewing proposed by Soriano (2007, pp. 190-198), the researcher transcribed the focus-group sessions, identified the main categories of topics dealt with by participants, and tagged the transcription according to a proposed code set. The full transcription of the sessions together with the topic tagging can be found on the author's PhD dissertation (Alonso, 2014b)

As stated above, the participants had been selected beforehand in accordance with our research criteria, i.e. they had to be professionals working in the translation sector. Given the qualitative and interpretative approach of our work, it was in no way intended that our sample should be representative of the translation industry as a whole. From the focus-group sessions we extracted the following profile descriptions:

Focus group 1:

- S1 (the "senior translator"): a professional translator with more than 30 years of experience, specialised in legal, financial and technical translation.

- S2 (the "translator-trainer"): a professional translator of general texts, also specialised in technical and medical translation, who has worked as both translator and trainer.

Focus group 2:

- S3 (the "freelance localiser"): a professional freelance translator with 12 years of experience, specialising in technical translation and localisation.

- S4 (the "project manager"): a professional translator and project manager heading a team of translators (Single Language Vendor). She had over 15 years of experience and habitually received briefs on diverse topics (mostly technical, localisation, insurance, tourism, etc.)

- S5 (the "in-house translator"): a professional translator with 8 years of experience with a Single Language Vendor, who has worked on many varieties of translations.

\section{Results}

In the following paragraphs, we present some of the results obtained from our analysis of the participant statements made during the focus-group sessions, which stress the prevalence of digital and virtual communication, as well as the existence of conflictive interactions when managing translation projects.

As indicated above, participants in the focus-group sessions discussed a wide range of topics, such as their way of approaching a translation brief, the tools they used, or details about their professional profiles; despite the interest 
and relevance of these topics, the scope of this paper is limited to the abovementioned negative interactions.

It should be noted that, in general, the participants in the focus groups alluded to tools (Internet, general tools and translation tools) as allies when approaching translation difficulties:

Our results seem to depict a scenario in which translation professionals, comfortably installed in the technological paradigm, use a wide variety of tools, both generic (Internet, Google, e-mail, chats, forums, Wikipedia, etc.) and specialised (online corpus, translation memory tools, electronic dictionaries, automated revision, etc.) (Alonso, 2015b, p. 316).

To add another argument to that beneficial perception, the nature of the relationships with other human agents - particularly with experts and translators or reviewers - involved in the translation process would also be positive in general terms (Alonso, 2014a). However, participants reported conflictive interactions both with human agents (mostly clients and project managers) and with tools (especially, email and translation portals). Thus, for example, given that freelance translators usually work outside the premises of the hiring company, the senior translator (S1) stressed the importance of maintaining an internal management system, a basic record of the translation brief's details:

S1: Basically, the first thing to do is obviously write down all relevant details of the brief, especially the person you have to contact for that brief, the person you talk to get paid or to iron out anything you don't understand, anything that's ambiguous or just plain wrong. That's the most important thing. (Focus group 1, lines 52-61).

The project manager (S4) also emphasized the need to have a management system within the translation agency. As we will show below, she repeatedly alluded to the lack of trust and to the prejudice she had towards project managers and clients.

S4: [...] we are finding external project management less and less trustworthy, so we try to manage our projects internally, doing our own revision and quality assessment [...] We use a project management tool, ProjectTest - you've probably heard of it; it's very similar to many others. [...] ProjectTest is our work base for the three phases of the project, right? Sometimes we also use Google Drive - it's not called Google Docs any more - to keep a record of upcoming projects, because ProjectTest doesn't allow you that option. You often say yes to a number of projects but then you don't receive them till much later, but the customers don't care: as far as they are concerned you said yes. That's the way things work here (...): even if they change the project dates, you've already accepted the project. So this is also a way of controlling time and planning out future time as much as possible. (Focus group 2, lines 222-330).

The translator-trainer (S2) also alluded to the telematic or virtual nature of communications between translation professionals and their clients. In this sense, he mentioned the existence of translation portals, i.e. sites incorporating web applications and social networking aimed at facilitating the outsourcing of translation services. The translator-trainer reported receiving his translation briefs through these virtual platforms which he accessed with a username and password. Apparently, the translator-trainer maintained stable relationships with his clients; he typically had a predefined profile (languages, specialisation, etc.) in his clients' portals, which enabled him to know in advance the type of texts he would have to translate: 
S2: [...] what I do with the companies I do the most work for is go to their web site and check if there is something for me. I log in with my username and password, and have a look at what's there. I already have my text profile. [...] So I go straight to the texts. I know what I'm going to find. (Focus group 1, lines 159-163).

We can see that, in principle, translation portals emerge as useful tools, since they help the translator predefine a profile indicating their languages, skills, tools, availability, etc. thus facilitating the outsourcing of a translation brief by the client. Likewise, the freelance localiser (S3) referred to these translation portals, as well as to email, as a way of receiving and managing her translation briefs and communications with her clients.

S3: I usually get my translation briefs by email (the project manager emails me, together with other translators if the translation is big) or via the intranet of companies that assign translations to different translators. (Focus group 2, lines 84-92)

However, one of the disadvantages of translation portals would be the opacity of the translation brief. Translators may have very little advance information about what is entailed, and only learn what the text is about once the brief is accepted:

S3: When I start translating, the first thing I usually do is try to find out what I have to translate, because sometimes, depending on the company and its confidentiality policy, etc., translators don't know what we are translating. So I try to get an overview of what it's all about. (Focus group 2, lines 99-105).

As in the case of the translator-trainer, the freelance localiser seemed to have stable relationships with her clients and reported receiving from them almost every necessary resource to carry out the translation brief (glossaries, translation memories, style guides, etc.)

S3: Well, talking about the difficulties involved in preparing a translation brief, most of my clients provide me with quite clear details about the number of words and so on. So I don't need to seek out that information unless it's a direct client. In that case I have to analyse the files, etc. (Focus group 2, lines 424-431).

The project manager (S4) introduced a relevant piece of detail regarding the way of approaching the management of a translation project - namely, that there is a difference depending on whether the client is direct or a large translation agency (vendor). When dealing with direct clients (companies outside the translation industry), the project manager explained that she had to devote a huge amount of time to communication with client, because they usually are not aware of their own needs and are unfamiliar with translation dynamics. The project manager's words suggest that her interactions with direct clients were ruled by mistrust:

S4: If it's a direct client, for me it's very (...) it takes me a long time, because I don't trust what the customer (...) They don't know what they want either. So you have to have it very clear, and make it very clear to them: "Will there be further versions of the document?" You have to have a free-flowing dialogue with them. In fact, people still work like that. So obviously the dynamics are different. If it's a direct client, first I have to make sure the client has sent me what they really need to translate and if it's the final version, etc. Once I have the actual documents that need translating, deadlines are very important, because, depending on the time available, I'll be able to manage the project one way or another. (Focus group 2, lines 152-176). 
When the client was a vendor, the project manager also reported receiving her translation briefs from virtual translation platforms. We note that, as well as the abovementioned advantages of these portals (immediate communication, easier and faster outsourcing or hiring of translations, etc.), participants also raised certain disadvantages, such as the already mentioned opacity - i.e. translators only learn the details of the translation brief (topic, number of words, tool to be used, etc.) once they have accepted it - thus forcing a negotiation and re-negotiation loop between the translator and the agency:

S3: When we are translating for a big agency, well, everybody (...). We usually work through the client's web portal. It's increasingly common for the client not even to send you an email; often they don't even give any advance warning of a project, they just send a short email saying: "You have -they don't even tell you the number of words, the deadline, etc.- that project waiting for you". And once you get into the portal, you see the deadline, and if possible you fight a bit to see if they can extend it, depending on the topic. (Focus group 2, lines 181-197).

In opinion of the project manager, together with the lack of transparency of portals, another challenge for translators is the increasing technological complexity of translation projects.

S4: Even if we can't start the project for two or three days, we check the translation memory, to make sure the word count is correct, that everything can be opened and that the client's instructions are clear for us, because instructions are often hieroglyphic and it's not easy to decipher what the client really wants. And since there are now more and more different CAT tools available, you have to be very clear about what version they want, whether they want the files cleaned-up or raw-translated, etc. All that, in advance. (Focus group 2, lines 301312).

It bears noting that the abovementioned features of translation projects complexity and opacity - produced by technology are also stressed by Alonso and Calvo (2015):

[Receiving skopos with the minimum information] is the reality for many translators working with translation agencies, particularly small and mediumsized agencies, where project management and provider communication processes are ripe for improvement. However, in other cases, translation agencies or vendors put a great deal of effort into preparing specifications and instructions for the translator. If we consider the project specifications a translator might receive, here we are faced not so much with the skopos disappearing, as with a super skopos: detailed style guides, software for the translation and technical configurations in which translation decisions affecting the format and medium are given, a general description of the target audience for the translation (for example, Spanish speakers from any country), glossaries and bibliographic sources to be consulted, together with basic order information (number of words, rate, date ordered and delivery date). (p. 143).

The project manager also alluded to the existence of tensions and mistrust produced by the lack of experience of translation vendors' project managers.

S4: In our experience, project managers often cheat a little; they don't give us all the information. The first thing they want is for you to accept the project and, once you've accepted it, you start to see the dark side of it. (Focus group 2, lines 197-203).

S4: [...] project managers are increasingly inexperienced and prepare increasingly poor packages; problems then crop up during the job and they want you to solve them on your own for the same price. (Focus group 2, lines 216220). 
Another of the difficulties referred by participants in relation to project management and communication with clients were the challenges of properly managing email.

S4: Difficulties? For example, communication with clients. I miss a tool capable of telling me what messages I've replied to and what messages I haven't. You may think it's silly, but what I do every morning is click 'Reply to all', leaving all the messages open and unwritten, and then little by little I try to (...). So, sometimes I have about 45 messages to reply to and that's difficult. (Focus group 2, lines 363-372).

Similarly, the in-house translator (S5) also reported problems of communication with clients. In her case, the lack of answer by clients to her queries caused her insecurity and dissatisfaction:

S5: In the last project I worked on, the biggest difficulty I found was the lack of communication with my client. For example, I had a lot of queries they didn't answer or I saw that they didn't show any interest in answering. That makes me feel insecure when I have to deliver a project. "Well, I've delivered it, but I don't feel $100 \%$ sure that it's perfect." There could be errors, that's normal, but if I find the client hasn't answered my questions and so on, that makes me feel kind of insecure. (Focus group 2, lines 400-420).

\section{Conclusions}

The following statements are presented as a means of opening up new paths of research and are not intended to be considered as definitive conclusions. In previous sections we mentioned some of the survey's shortcomings, such as its language/country bias and its limited scope and sample.

Nevertheless, we believe our work has qualitative value, with the added merit of documenting a reality that to date has been studied very little. With this descriptive approach in mind, we will try to identify certain trends to better understand how translation projects are managed and the existing sources of conflict in the computer-mediated translation market.

As narrated in the focus groups, whereas positive interaction and good perception of technology and colleagues (translators, reviewers, experts, etc.) takes place in the production phase of the translation process (basically, when translators translate), conflict in translation projects seems to be attached to management and communication with clients and project managers in a computer-mediated context of increasing technological complexity. This behaviour has also been observed in professional settings by Kuznik and Verd (2010) and Risku (2004) among others. According to Abdallah (2012, p.42), this emphasises "the ironic fact that translating is not considered a core competence in translation companies". As a result, it becomes apparent that translator training should pay more attention to instrumental and interpersonal skills (Morón, 2005) to prepare future translators "for the conflicting expectations that often arise in production networks" (Abdallah, 2011, p. 130).

The computer-mediated nature of translation markets has some evident benefits: communication is faster, direct, and cheaper, while outsourcing is easier because translators can be recruited according to their specific profile (languages, skills, experience, etc.).

However, as outlined above, conflictive interactions of translators with translation portals apparently have their origin in the opacity of these portals, because they do not allow translators to obtain much information about the brief beforehand. In addition, translators would commonly perceive the messages received through these portals as impolite, too direct and 
dehumanising. Conversely, the opposite situation is not positive either, since super skopos (briefs containing an extremely detailed guide of the translation project) are also a source of tensions.

Interactions among professionals (between translators and clients and/or project managers) seem to be ruled by lack of trust and prejudice. In this sense, translators may perceive in many cases that clients (even direct clients) are not aware of their own needs and that project managers are inexperienced, unscrupulous, and even irresponsible and unsupportive to them. In our view, these facts cannot be attributed solely to the inner structure of globalised translation production networks, but also to a common (mis)conception of what a translator is. This probably relates directly to revisited ideas within Translation Studies, such as the identity of the translator, or the perceived nature of translation in society. As Abdallah (2012) has asserted:

It is, therefore, appropriate to examine how such a central actor [the translator] perceives translation production networks, particularly since translators' work has been hitherto considered largely invisible (Venuti 1995, Simeoni 1998: 12, Kaisa Koskinen 2000: 89-106, see also Dam and Zethsen 2008: 73) and their position has become marginalized in the industry (Austermühl 2005, Jääskeläinen 2007). For these reasons, translators can be rightfully considered a mute, silenced group in society. (p. 1).

In translation markets, as in other computer-mediated contexts, conflict that emanates from email communication is due to information asymmetries and unfulfilled expectations. Whereas in some cases communication with clients is very time-consuming, in other cases translators feel frustrated by the lack of answers from their clients.

Interestingly, in our focus groups none of the subjects mentioned translation fees - historically a subject of long and heated debates with many questions still to be explored, as witnessed over the last few decades.

As a result of the conflicts arising in the management of translation projects and their communication, a loop of continuous negotiation and renegotiation may be taking place among the actors of the translation industry (clients, translators, vendors) in a manner resembling a bazaar.

Finally, this qualitative research could serve as a basis for further research with applications for the development of management and communication software, training programs for managers in globalised settings, as well as for translators and negotiators.

\section{Acknowledgments}

The author gratefully acknowledges the participants of the focus group sessions for their generosity.

\section{References}

Abdallah, K. (2007). Managing trust: Translating and the network economy. Meta: Journal des Traducteurs / Meta: Translators' Journal, 52(4), 673-687. doi: 10.7202/017692ar.

Abdallah, K. (2011). Towards empowerment: Students' ethical reflections on translating in production networks. The Interpreter and Translator Trainer, 5(1), 129-154. doi: 10.1080/13556509.2011.10798815.

Abdallah, K. (2012). Translators in production networks. Reflections on agency, quality and ethics. Doctoral dissertation supervised by Dr. K. Koskinen, Joensuu, Finland. Publications of the University of Eastern Finland. Retrieved from: 
http://epublications.uef.fi/pub/urn_isbn_978-952-61-0609-0/urn_isbn_978-95261-0609-0.pdf.

Alonso, E. (2014a). Interacciones sociales y tecnológicas en el entorno profesional de la traducción [Social and technological interactions in the professional context of translation]. Tonos Digital: Revista de Estudios Filológicos, 2(27). Retrieved from: http://www.tonosdigital.es/ojs/index.php/tonos/article/view/1124/692.

Alonso, E. (2014b). Traducción y tecnología. Análisis del uso y percepción de Wikipedia por parte de los profesionales de la traducción [Translation and Technology. Use and perceptions of Wikipedia in the professional context of translation]. Doctoral dissertation supervised by Dr. M.A. Vázquez Medel and Dr. A. Fuentes, Universidad de Sevilla, Spain. Retrieved from: http://fondosdigitales.us.es/tesis/autores/2576/

Alonso, E. (2015a). Analysing translation professionals in the information society and their use and perceptions of Wikipedia. JoSTrans: The Journal of Specialised Translation, 23, 89-116. Retrieved from: http://www.jostrans.org/issue23/ art_alonso.pdf

Alonso, E. (2015b). Google and Wikipedia in the professional translation process: A qualitative work. Procedia - Social and Behavioral Sciences. 32nd International Conference of the Spanish Association of Applied Linguistics (AESLA): Language Industries and Social Change, 173, 312-317. Retrieved from: http://www.sciencedirect.com/science/article/pii/S1877042815013804.

Alonso, E., \& Calvo, E. (2015). Developing a blueprint for a technology-mediated approach to Translation Studies. Meta: Journal des Traducteurs / Meta: Translators’ Journal, 60(1), 135-157. doi: 10.7202/1032403ar.

Calvo, E. (2015). Scaffolding translation skills through situated training approaches: progressive and reflective methods. The Interpreter and Translator Trainer, 9(3), 306-322. doi: 10.1080/1750399X.2015.1103107.

Dam, H. V., \& Zethsen, K. K. (2011). The status of professional business translators on the Danish market: A comparative study of company, agency and freelance translators. Meta: Journal des Traducteurs / Meta: Translators' Journal, 56(4), 976-997. doi: 10.7202/1011263ar.

Desilets, A., Melançon, C., Patenaude, G., \& Brunette, L. (2009). How translators use tools and resources to resolve translation problems: An ethnographic study. MT Summit XII - Workshop: Beyond Translation Memories, Ottawa. Retrieved from: http://www.mt-archive.info/MTS-2009-Desilets-2.pdf.

Gouadec, D. (2007). Translation as a profession. Amsterdam/Philadelphia: John Benjamins.

Guerberof Arenas, A. (2013). What do professional translators think about postediting? JoSTrans: The Journal of Specialised Translation, 19, 75-95. Retrieved from: http://www.jostrans.org/issue19/art_guerberof.pdf.

Hofstede, G., Hofstede, G. J., \& Minkov, M. (2005). Culture and organizations: Software of the mind. USA: McGraw-Hill.

Horton, J. J. (2010). Online Labor Markets. In A. Saberi (Ed.) Internet and network economics. (pp. 515-522). New York: Springer-Verlag Berlin Heidelberg. doi: 10.1007/978-3-642-17572-5_45.

Hössjer, A., \& Severinson Eklundh, K. (2009). Making space for a new medium: On the use of electronic mail in a newspaper newsroom. Computer Supported Cooperative Work 18, 1-46. doi: 10.1007/s10606-008-9082-7.

Katan, D. (2009). Translation theory and professional practice: A global survey of the great divide. Hermes-Journal of Language and Communication Studies, 42, 111154. Retrieved from: http://download2.hermes.asb.dk/archive/download/ Hermes-42-7- katan_net.pdf.

Kuznik, A., \& Verd, J. M. (2010). Investigating real work situations in translation agencies. Work content and its components. Hermes-Journal of Language and Communication Studies, 44, 25-43. Retrieved from: http://download2.hermes. asb.dk/archive/download/Hermes-44-kuznik\&verd.pdf.

Lagoudaki, E. (2006). Translation memory survey 2006: Users’ perceptions around TM use. Translating and the Computer 28: Proceedings of the Twenty-Eighth International Conference on Translating and the Computer, 16 - 17 November 2006, London. London: ASLIB. Retrieved from: http://www.mt-archive. info/ Aslib-2006-Lagoudaki.pdf. 
Mayoral, R. (2001). Aspectos epistemológicos de la traducción. Castellón de la Plana: Publicacions de la Universitat Jaume I.

Monzó Nebot, E. (2006). ¿Somos profesionales? Bases para una sociología de las profesiones aplicada a la traducción. In A. Parada \& O. Díaz Fouces (Eds.), Sociology of translation (pp. 155-176). Vigo: Servizo de Publicacións da Universidade de Vigo.

Morón, M. (2005). La relevancia de los factores interpersonales en traducción: nuevas fuentes para el diseño curricular. In M.L. Romana García (Ed.), Actas del II Congreso Internacional de la Asociación Ibérica de Estudios de Traducción e Interpretacio (pp. 129-140). Madrid: AIETI. Retrieved from: http://www.aieti.eu /pubs/actas/II/AIETI_2_MAMM_Relevancia.pdf.

Olohan, M. (2011). Translators and translation technology: The dance of agency. Translation Studies, 4(3), 342-357. doi: 10.1080/14781700.2011.589656.

Panteli, N., \& Sockalingam, S. (2005). Trust and conflict within virtual interorganizational alliances: A framework for facilitating knowledge sharing. Decision Support Systems 39, 599-617. doi: 10.1016/j.dss.2004.03.003.

Risku, H. (2004). Translationsmanagement. Interkulturelle fachkommunikation im informationszeitaler. Tübingen (Germany): Gunter Narr Verlag.

Robson, C. (2011). Real world research: A resource for users of social research methods in applied settings ( $3^{\text {rd }}$ ed.). Chichester (U.K.): Wiley.

Soriano, I. (2007). Evaluación de un programa de movilidad en la formación de traductores. Doctoral dissertation supervised by Dr. D. Kelly, Universidad de Granada, Spain. Retrieved from: http://hera.ugr.es/tesisugr/16713266.pdf

Steinfield, C., Chan, A. P., \& Kraut, R. (2006). Computer mediated markets: An introduction and preliminary test of market structure impacts. Journal of Computer-Mediated Communication 5(3), doi:10.1111/j.1083-6101.2000. tb00345.

Stoeller, W. (2011). Translation and localization project management. In K. J. Dunne \& E. S. Dunne (Eds.), Perspectives on localisation (pp. 289-318). Amsterdam/Philadelphia: John Benjamins.

Torres Domínguez, R. (2012). 2012 Use of translation technologies survey. Mozgorilla. Retrieved from: http://mozgorilla.com/en/texnologii-en-en/ translation-technologies-survey-results/.

Turnage, A. K. (2007). Email flaming behaviors and organizational conflict. Journal of Computer-Mediated Communication, 13(1), 43-69. doi: 10.1111/j.10836101.2007.00385.x

Yahaya, F. (2008). Managing complex translation projects through virtual spaces: a case study. ASLIB Translating and the Computer 30, Nov. 27-28, 2008, London, UK. Retrieved from: http://www.mt-archive.info/Aslib-2008-Yahaya.pdf. 